\title{
Effect of DCRP and DCSP Polarity on the Depth of Penetration of SMAW on Low Carbon Steel ASTM A36 Using E7018 Electrode
}

\author{
Ma'mun Hidayat ${ }^{1}$, Helleni Febnesia ${ }^{2}$, Sulaeman Deni Ramdani ${ }^{3}$ \\ ${ }^{1}$ Central for Development of Vocational Serang, Ministry of Manpower, Jl. Raya Pandeglang No. 3, 42118, \\ Serang, Indonesia \\ ${ }^{2.3}$ Mechanical Engineering Education, Sultan Ageng Tirtayasa University, Jl. Ciwaru Raya No.25, 42117, \\ Serang, Indonesia \\ *Corresponding author: s.deni.ramdani@untirta.ac.id
}

\begin{abstract}
The study aims to determine the level of penetration depth using SMAW (Shielded Metal Arc Welding) Process based on the polarity type of DCRP (Direct Current Reverse Polarity) and DCSP (Direct Current Straight Polarity). This research used ASTM A36 low carbon steel plate with thickness of $6 \mathrm{~mm}$ and length of $200 \mathrm{~mm}$, Electrode E7018 LB-52-18 Ø $3.2 \mathrm{~mm}$, and with current parameters of 90 A, 100 A, 110 A, 120 $\mathrm{A}$ and $130 \mathrm{~A}$ and $70^{\circ}$ welding arc angle. The method used the experimental research. Data collection techniques applied direct observation techniques and descriptive statistical data analysis techniques. Testing the penetration depth of the welds with a macrographic test was conducted by an optical microscope. The test results show that DCRP has more depth than DCSP when the current is $90 \mathrm{~A}$ with a difference of 0.38 $\mathrm{mm}$. When the current is $100 \mathrm{~A}$, DCRP is deeper with a difference of $0.312 \mathrm{~mm}$ compared to DCSP. The third experiment, with a current of 110 A DCRP, was deeper with a difference of $0.05 \mathrm{~mm}$ compared to DCSP. During the fourth and fifth experiments, DCRP was deeper with a difference of $0.21 \mathrm{~mm}$ compared to DCSP at $120 \mathrm{~A}$ and DCRP was $0.324 \mathrm{~mm}$ deeper than DCSP at $130 \mathrm{~A}$. It can be concluded that the effect of DCRP and DCSP polarity on the depth of penetration using E7018 electrodes and ASTM low carbon steel A36, DCRP polarity has a deeper penetration depth compared to DCSP.

Copyright $\odot$ 2021. Journal of Mechanical Engineering Science and Technology.

Keywords: DCRP, DCSP, macrographic test, penetration depth, SMAW
\end{abstract}

\section{Introduction}

In current era, the development of the technology sector was accompanied by the development of the industrial and construction sectors [1]. The industrial and construction sectors certainly cannot be separated from the welding process. Welding is a process of joining two materials permanently by melting two materials that will be joined with added material or not, which will cool together to become welding deposits [2].

The welding process belongs to a special process classification because the process and its manufacture are directly related to the quality of the final product. Failure of the weld joint is fatal, meaning that if the weld joint is not suitable, it can be classified as a failure of the product itself [3]. One of the welding processes, namely Shielded Metal Arc Welding or commonly abbreviated as SMAW, is a welding process that uses a heated metal arc to melt into molten metal as an added material and blend with the specimen material being welded [4]. The SMAW welding process is a process that is often used because it is simple and has a relatively low cost in the preparation of workpieces, materials and personal protective 
equipment (PPE) [5]. The welding process can occur due to obstacles that flow between the material and the added material, which causes heat so that the materials and added materials will melt and coalesce and cool together [2]. As a result of the process, the metal in the vicinity of the weld undergoes rapid thermal cycling and causes complex metallurgical changes, deformations, and thermal stresses [6][7]. Therefore, it is closed to the problem of toughness, weld defects, cracks, and others, which generally have a fatal impact on the safety of construction welding. So, the deeper the penetration, the more the fusion between the material and the added material. It will also affect the strength of the weld [3].

The area affected by the thermal when the arc ignites from the welding process is called the penetration. Penetration consists of a mixture of specimen metal and added material from the welding arc in the welding process [8]. To get the best welding results, it required careful preparation. The welding process starts from the preparation of materials and tools to cooling the material, which greatly determines the quality of the weld. Preparation processes include creating welding process stages, and the quality of the tools and materials [1]. The welding process results in the emergence of residual stress in the form of stress in the fusion zone and HAZ (Heat Affected Zone) and tensile stresses in the weld area [8]. The HAZ is an area of the specimen metal adjacent to the added material in the welding process, which undergoes a thermal cycle of heating and cooling with a certain time and speed [4].

The SMAW welding process is at the top of the cluster in the fusion welding process due to its flexibility and cost-effectiveness. This process is needed to construct steel-framed buildings, shipbuilding, motor vehicle manufacturing, power plants, and other industries [6]. Of course, welding in the shipbuilding construction sector has a very important role [1]. In the field of shipbuilding, welding functions as a process that connects ship parts that have been designed in such a way and connect when the repair process occurs on the ship [6]. The results of welding with the right methods and conditions will increase the results of the increasingly fused welds.

ASTM A36 is a type of low carbon steel commonly applied in welding and power plant construction. ASTM A36 low carbon steel is one of the commonly applied as structural hotrolled steels. The type of carbon steel material has special characteristics which are relatively inexpensive and highly recommended for the welding process [9]. ASTM A36 carbon steel plate is included in the mild carbon steel category because it has good enough strength, and its shape can be changed easily by a machine or by the SMAW welding process [9]. Another advantage of ASTM A36 low carbon steel plate is that it can accept the galvanic coating process, leading to high-quality iron resistance from corrosion [4]. Electric polarity is divided into 3 types, namely alternating current $(\mathrm{AC})$ polarity, direct current polarity (DCRP \& DCSP). In the current study, the welding process uses SMAW using DCRP and DCSP polarity. DCSP (Direct Current Straight Polarity) is when the electrode handlebar is connected to the negative pole of the welding machine while the positive pole is connected to the material to be welded. DCRP (Direct Current Reverse Polarity) is when the electrode handlebar is connected to the positive pole of the welding machine while the negative pole is connected to the material to be welded [10].

Several studies stated that DCRP and DCSP resulted in a temperature difference of $4200^{\circ} \mathrm{C}$ and $3800^{\circ} \mathrm{C}$ [8]. Another factor that affects the polarity of DCRP results in deeper penetration of $2 / 3$ compared to a DCSP of $1 / 3$ due to the flow of electrons flowing from the positive pole of the welding machine to the negative pole while the negative ions coming from the negative pole to the positive pole welding machine. This process affects the heat distribution that occurs in the welding process [11]. 
Direct current has the characteristic of a stable electric flow so that it is easy to use in the SMAW welding process, especially on thin metals. The temperature produced by the DCRP polarity and the DCSP polarity is $4200^{\circ} \mathrm{C}$ and $3800^{\circ} \mathrm{C}$, respectively. The data indicates that the DCRP polarity will have deeper penetration than the DCSP polarity because the heat impact exerted by the DCRP polarity is greater than that of DCSP [8].

Welding wire or electrodes is an added material in the SMAW binder process. Many welder use the type of electrode E7018 LB-52- 18 with a diameter of $3.2 \mathrm{~mm}$. In accordance with the electrode code E7018, the electrode is included in the type of low hydrogen electrode. The number 70 in E7018 shows the minimum tensile strength of $70 \mathrm{ksi}$. Number 1 on the E7018 indicates that electrode can be applied for various welding positions [12]. The last number on the E7018 shows the type of electrode as well as its composition and use of the welding current, meaning that the number 8 shows that the low-hydrogen electrode type is made of iron powder [12]. E7018 electrode storage in a dry and airtight place. It is recommended to use the oven at $300^{\circ} \mathrm{C}-350^{\circ} \mathrm{C}$ for $30-60$ minutes [13].

The electrode with type E7018 consists of a layer of high calcium carbonate (limestone) and calcium fluoride (Fluorspar). They can make the slag layer more fluid than rutile coating. This is the reason why the process of cooling and freezing welds in a vertical overhead position is faster. These electrodes are applied for welding fabricated parts where higher weld quality, good mechanical properties and resistance to cracking are required because of the high strain required [14]. The study aims to prove the effect of polarity on the depth of penetration in the SMAW welding process using E7018 LB 52-18 electrodes $\varnothing$ $3.2 \mathrm{~mm}$, and ASTM A36 low carbon steel with an electric current of $90 \mathrm{~A}, 100 \mathrm{~A}, 110 \mathrm{~A}$, $120 \mathrm{~A}$, and $130 \mathrm{~A}$ with a welding arc angle of $70^{\circ}$.

\section{Material and Method}

The study used an experimental research method. The observation technique which is done is direct observation technique by descriptive data analysis technique. The direct observational observation technique means that the researcher observes the research process directly. While the technique of descriptive statistical data analysis means that the researcher describes the research results that have been tested. Testing of speciment was conducted by macrographic testing or commonly known as macrostructure testing. The experiment study uses two ASTM A36 low carbon steel plates with a thickness of $6 \mathrm{~mm}$ with a length of 200 $\mathrm{mm}$, and the type of electrode E7018 LB-52-18, which has a diameter of $\varnothing 3.2 \mathrm{~mm}$. The tools in the welding process are welding helmets, hand gloves, safety wear packs and Lincorn Electric welding machines with the Speedtec 405SP type. The tools and materials during the testing process are Autosol liquid, etching solution, rags, cutting machines, grinding machines, and optical microscopes as instruments in macrostructure testing.

The location of the data collection process uses the SMAW welding process. which is carried out at the SMAW Workshop, BBPLK Serang. The testing process uses macro structure testing, which is carried out at the NDT Testing Building, BBPLK Serang. Data collection techniques used direct observation techniques with descriptive statistical data analysis. The steps in the research process to determine the effect of DCRP and DCSP polarity in SMAW welding on penetration depth of ASTM A36 low carbon steel plate using E7018 LB-52-18 electrodes is shown in Figure 1.

The initial stage of study was to determine the problem and the objectives that want to be achieved. This study was conducted to determine the effect of polarity on the depth of penetration in the SMAW using electrode E7018 LB-52-12 $\varnothing 3.2 \mathrm{~mm}$ with a welding arc tilt 
angle of $70^{\circ}$ and the macrographic test used an optical microscope with a variation. The electric currents applied in welding were 90 A, 100 A, 110 A, 120 A, 130 A.

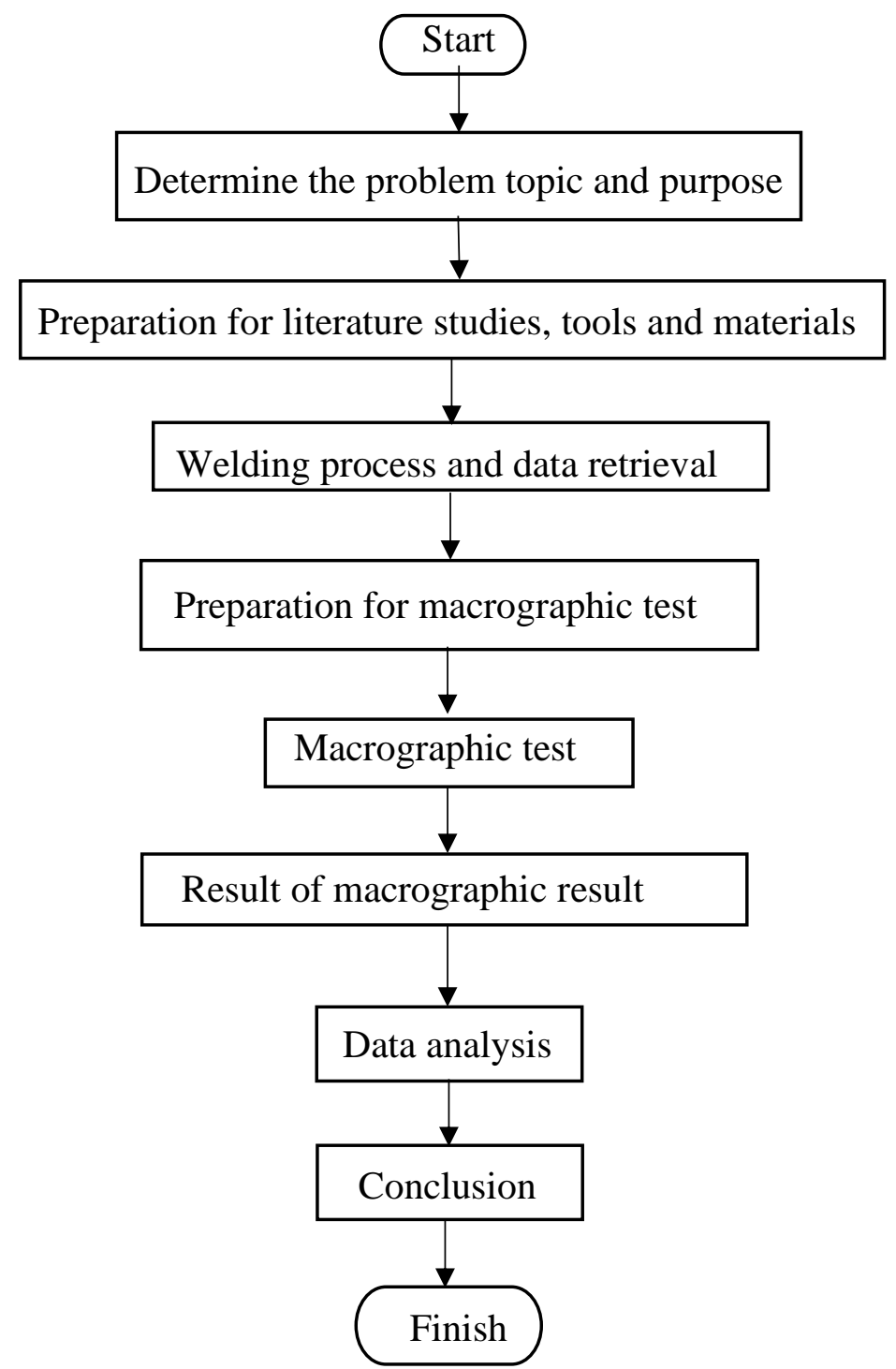

Fig. 1. Flowchart of research design

In the process of data collection, the tools and materials must meet the feasibility standard. The tools in this study were a set of SMAW welding machines, wear packs, welding helmets, hand gloves, slag hammers, steel brushes, cloth wipes, automatic cutting machines, grinding machines, 2 drop pipettes and optical microscopes, which are carried out for macrostructure testing. The materials in the data collection and testing process were two ASTM A36 low carbon steel plates with a thickness of $6 \mathrm{~mm}$ and $200 \mathrm{~mm}, 1$ box electrode E7018 LB-52-18, sandpaper with a roughness level of 100 - 400 grit, Autosol, Nitric Acid, and alcohol.

The data collection process was carried out by direct observation with a predetermined standard welding instrument. The standard of welding results determined, namely the length of the welding line must be straight with a length of $200 \mathrm{~mm}$, Interpass $<200{ }^{\circ} \mathrm{C}$, no visual 
welding defects. Collecting data applied the direct observation technique that the researcher directly observes and records all phenomena during the data collection process. Data were collected by measured the depth of penetration of each specimen. Specimen preparation applied a sandpaper and polishing machine that used sandpaper with various levels of fineness to 400 grit which functions to smooth the area of the specimen to be tested.

Testing the macrostructure itself is part of the metallographic process. Macro or macrographic structure testing is a test that is carried out to study the structure of metals and their alloys directly by the eye or lenses that are magnified up to 20 times (20: 1) [15] [16]. The results of testing of macro or macrographic structure are called macrostructure. The function of metallographic test is to determine the main structure of the specimen metal, the HAZ area and the area of penetration or penetration. Macrographic test puts more emphasis on the visual state of the specimen at a more detailed scale than with the naked eye [15].

In macrographic test process, initially, the specimen to be tested was cut according to the conditions and position of the specimen to be observed. Then the sanding and polishing process with sandpaper up to 400 the polishing stage also the grits. In Autosol Metal Polish then the final stage is polished with an etching solution consisting of $98 \%$ ethanol and $2 \%$ nitric acid, then cleaned with running water and cloth [17]. The etching solution serves to cause phase or grain boundaries in the specimen area. Then, process use an optical microscope which has a magnification up to 15 times for observing the specimen structure more clearly. The data analysis technique in the study was the quantitative descriptive data analysis technique. The resulting data was a comparison of the value of the penetration depth between DCSP and DCRP for each of the current variations of 90 A, 100 A, 110 A, 120, and $130 \mathrm{~A}$.

\section{Results and Discussions}

The experimental was carried out in SMAW welding process with two types of polarity, namely DCRP and DCSP, with electrodes of E7018 LB-52-18 $\emptyset 3.2 \mathrm{~mm}$ and a length of 200 $\mathrm{mm}$, low carbon steel ASTM A36, a welding arc angle of $70^{\circ}$, and a large variation of current $90 \mathrm{~A}, 100 \mathrm{~A}, 110 \mathrm{~A}, 120 \mathrm{~A}$, and $130 \mathrm{~A}$. In the data collection process, the amount of voltage, travel speed and interpass temperature lower than $200^{\circ} \mathrm{C}$ were used as supporting data to measure the depth of penetration. The results of the welding process are shown in Table 1 and Table 2.

Table 1. Data travel speed, interpass temperature and amount of voltage (DCRP)

\begin{tabular}{lcrr}
\hline Voltage & Welding Current & Travel Speed & Interpass Temperature \\
\hline $22.2 \mathrm{~V}$ & $90 \mathrm{~A}$ & $126.32 \mathrm{~mm} / \mathrm{min}$ & $26.3{ }^{\circ} \mathrm{C}$ \\
$24.1 \mathrm{~V}$ & $100 \mathrm{~A}$ & $133.33 \mathrm{~mm} / \mathrm{min}$ & $89.6^{\circ} \mathrm{C}$ \\
$24.5 \mathrm{~V}$ & $110 \mathrm{~A}$ & $155.84 \mathrm{~mm} / \mathrm{min}$ & $184.3^{\circ} \mathrm{C}$ \\
$24.6 \mathrm{~V}$ & $120 \mathrm{~A}$ & $150 \mathrm{~mm} / \mathrm{min}$ & $166.6^{\circ} \mathrm{C}$ \\
$25.6 \mathrm{~V}$ & $130 \mathrm{~A}$ & $171.43 \mathrm{~mm} / \mathrm{min}$ & $177.9^{\circ} \mathrm{C}$ \\
\hline
\end{tabular}


Table 1 and Table 2 show the greater the current, the greater the voltage and travel speed and the resulting interpass temperature. For comparison, the travel speed DCSP has a speed which is greater than the polarity type DCRP, but for a large comparison the DCRP voltage has a large voltage compared to DCSP.

Table 2. Data travel speed, interpass temperature and amount of voltage (DCSP)

\begin{tabular}{lcrr}
\hline Voltage & Welding Current & Travel Speed & Interpass Temperature \\
\hline $22.5 \mathrm{~V}$ & $90 \mathrm{~A}$ & $153.85 \mathrm{~mm} / \mathrm{min}$ & $28.9^{\circ} \mathrm{C}$ \\
$22.7 \mathrm{~V}$ & $100 \mathrm{~A}$ & $136.36 \mathrm{~mm} / \mathrm{min}$ & $12.3^{\circ} \mathrm{C}$ \\
$22.9 \mathrm{~V}$ & $110 \mathrm{~A}$ & $160 \mathrm{~mm} / \mathrm{min}$ & $158.5^{\circ} \mathrm{C}$ \\
$23.7 \mathrm{~V}$ & $120 \mathrm{~A}$ & $176.47 \mathrm{~mm} / \mathrm{min}$ & $122.4^{\circ} \mathrm{C}$ \\
$23.9 \mathrm{~V}$ & $130 \mathrm{~A}$ & $196.72 \mathrm{~mm} / \mathrm{min}$ & $131.5^{\circ} \mathrm{C}$ \\
\hline
\end{tabular}

After collecting the data during the welding process, then the macrographic observation was carried out under an optical microscope to look at a depth of penetration of the welding process. Observation results is ahown at Table 3 and Table 4.

Table 3. Data of penetration depth DCRP

\begin{tabular}{rrrrrr}
\hline DCRP & $90 \mathrm{~A}$ & $100 \mathrm{~A}$ & $110 \mathrm{~A}$ & $120 \mathrm{~A}$ & $130 \mathrm{~A}$ \\
\hline 1.1 & 1.38 & 1.46 & 1.45 & 1.57 & 3.38 \\
1.2 & 1.66 & 1.82 & 1.82 & 2.02 & 2.57 \\
1.3 & 1.62 & 1.71 & 1.71 & 2.21 & 2.18 \\
1.4 & 1.46 & 1.64 & 1.64 & 1.97 & 2.06 \\
1.5 & 1.47 & 1.56 & 1.59 & 2.11 & 2.06 \\
\hline Total & 7.59 & 8.19 & 8.21 & 9.88 & 12.25 \\
Average & 1.518 & 1.638 & 1.642 & 1.976 & 2.45 \\
\hline
\end{tabular}

*units in $(\mathrm{mm})$

Table 3 shows the depth of penetration in the SMAW welding process with various type of polarity DCRP. In experiment DCRP 1.1, the resulting penetration depth is 1.38 $\mathrm{mm}$ when the current is $90 \mathrm{~A}$ (Figure 2), $1.46 \mathrm{~mm}$ when the current is $100 \mathrm{~A}$ (Figure 3), $1.45 \mathrm{~mm}$ when the current is $110 \mathrm{~A}$ (Figure 5), $1.57 \mathrm{~mm}$ when the current is $120 \mathrm{~A}$ (Figure 5), and 3, $38 \mathrm{~mm}$ when the current is $130 \mathrm{~A}$ (Figure 6). The test results tend to continue to experience an increase in penetration depth and the increase in current magnitude. But there was a decrease that was not too significant when the current was $110 \mathrm{~A}$ with a decrease in the depth level of $0.01 \mathrm{~mm}$. It is indicated as a human error because the results are not significant. 


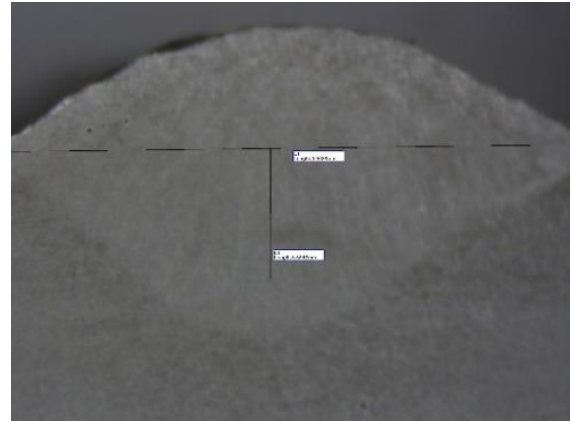

Fig. 2. Penetration depth 1.1 when current $130 \mathrm{~A}$

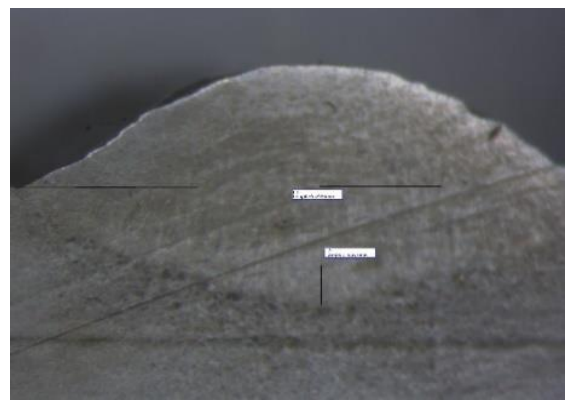

Fig. 4. Penetration depth 1.3 when current $130 \mathrm{~A}$

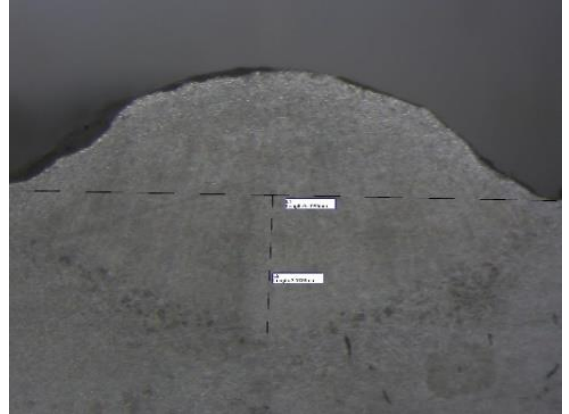

Fig. 3. Penetration depth 1.2 when current $130 \mathrm{~A}$

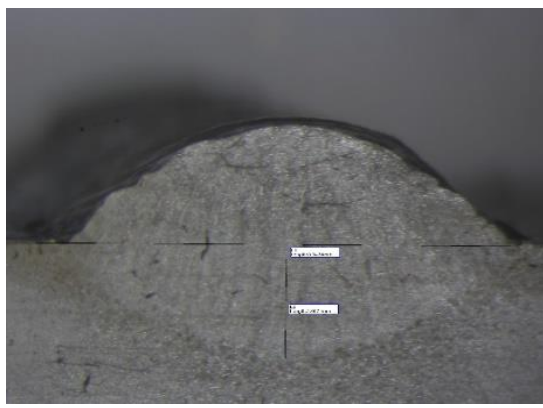

Fig. 5. Penetration depth 1.4 when current $130 \mathrm{~A}$

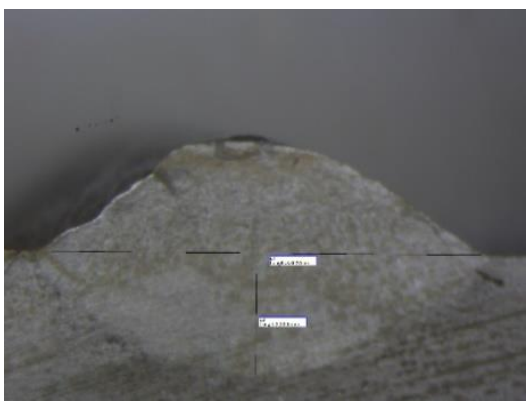

Fig. 6. Penetration depth 1.5 when current $130 \mathrm{~A}$

In the second, third, fourth and fifth experiments, when the currents were $100 \mathrm{~A}, 110$ A, $120 \mathrm{~A}$ and $130 \mathrm{~A}$, it always had a deeper penetration depth as the current strength increased. The influence of these current is due to the fact that the welding process greatly affects the mechanical properties and the tensile strength of the welded steel tends to decrease, but the toughness of the material increases because it increases the percentage of the acicular ferrite phase. Because if the greater the current given to the welding process, it will increase the angle of distortion that occurs in the welding results. 


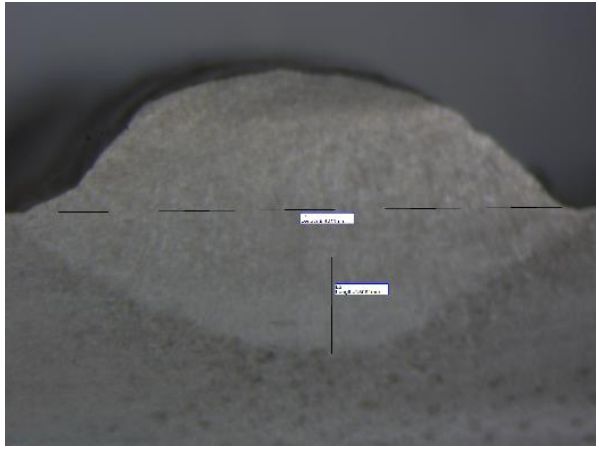

Fig. 7. Penetration depth 2.1 when current $130 \mathrm{~A}$

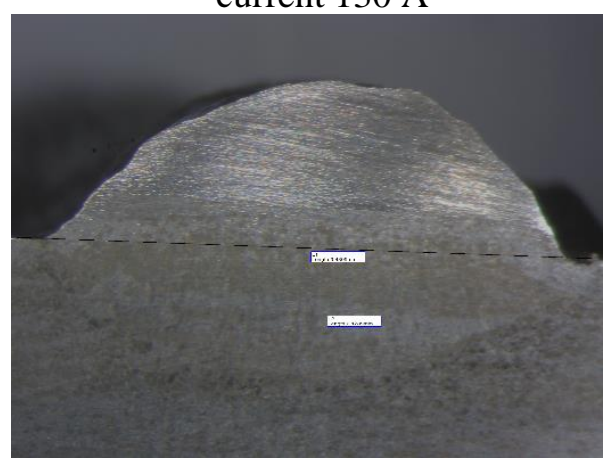

Fig. 9. Penetration depth 2.3 when current $130 \mathrm{~A}$

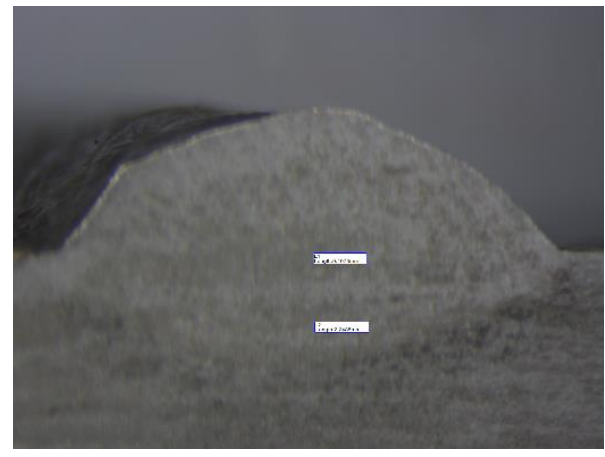

Fig. 8. Penetration depth 2.2 when current $130 \mathrm{~A}$

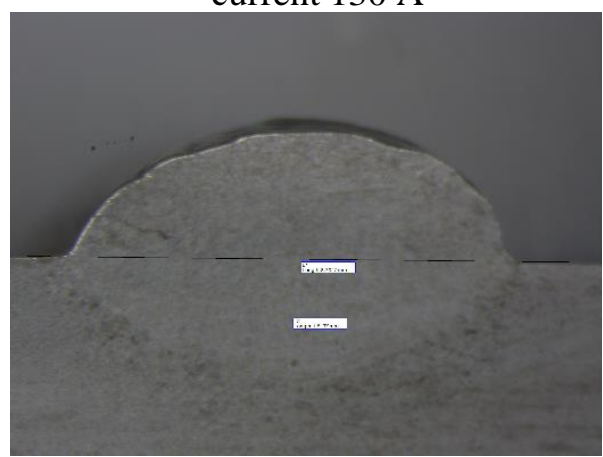

Fig. 10. Penetration depth 2.4 when current $130 \mathrm{~A}$

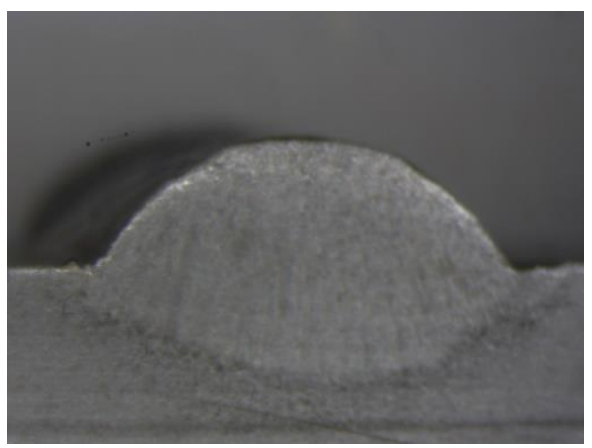

Fig. 11. Penetration depth 2.5 when current $130 \mathrm{~A}$

Table 4 that shows the results of the depth of penetration in SMAW welding process at various type of polarity DCSP. In experiment DCSP 2.1, the resulting penetration depth is $1.29 \mathrm{~mm}$ when the current is $90 \mathrm{~A}$ (Figure 7), $1.3 \mathrm{~mm}$ when the current is $100 \mathrm{~A}$ (Figure 8), $2.14 \mathrm{~mm}$ when the current is 110 A (Figure 9), $1.93 \mathrm{~mm}$ when the current is 120 A (Figure 10) and 2, $3 \mathrm{~mm}$ when the current is $130 \mathrm{~A}$ (Figure 11). The test results tend to continue to experience an increase in penetration depth and the increase in current magnitude. But there was a decrease that was not too significant when the current was $120 \mathrm{~A}$ with a decrease in the depth level of $0.28 \mathrm{~mm}$. It is indicated as a human error because the results are not significant. 
In the second, third, fourth and fifth experiments in Table 4, when the currents were 100 A, $110 \mathrm{~A}, 120 \mathrm{~A}$ and $130 \mathrm{~A}$, it always had a deeper penetration depth as the current strength increased. The influence of these current is due to the fact that the welding process greatly affects the mechanical properties, and the tensile strength of the welded steel tends to decrease, but the toughness of the material increases because it increases the percentage of the acicular ferrite phase. Because if the greater the current given to the welding process, it will increase the angle of distortion that occurs in the welding results.

Table 4. Data of penetration depth DCSP

\begin{tabular}{rrrrrr}
\hline DCSP & $90 \mathrm{~A}$ & $100 \mathrm{~A}$ & $110 \mathrm{~A}$ & $120 \mathrm{~A}$ & $130 \mathrm{~A}$ \\
\hline 2.1 & 1.29 & 1.30 & 2.14 & 1.93 & 2.30 \\
2.2 & 0.95 & 1.18 & 1.46 & 1.84 & 2.23 \\
2.3 & 1.03 & 1.43 & 1.80 & 1.81 & 2.13 \\
2.4 & 1.18 & 1.30 & 0.98 & 1.54 & 1.97 \\
2.5 & 1.24 & 1.42 & 1.58 & 1.71 & 2.00 \\
\hline Total & 5.690 & 6.630 & 7.960 & 8.830 & 10.630 \\
Average & 1.138 & 1.326 & 1.592 & 1.766 & 2.126 \\
\hline * units in $(\mathrm{mm})$ & & & &
\end{tabular}

Table 5 and Figure 12 show that the depth of penetration is based on the type of polarity of DCRP and DCSP observed by a macrographic test with an optical microscope tool. The results show that the polarity of DCRP at 90 A has a depth of $1.518 \mathrm{~mm}$ and a difference of $0.38 \mathrm{~mm}$ is deeper than DCSP, which only has a depth of $1.138 \mathrm{~mm}$, the polarity of DCRP at $100 \mathrm{~A}$ has a depth of $1.638 \mathrm{~mm}$ and a difference of $0.312 \mathrm{~mm}$ is deeper than DCSP which only has $1.326 \mathrm{~mm}$ depth.

Table 5. Average penetration depth

\begin{tabular}{rrrr}
\hline Current & DCRP & DCSP & Difference in depth \\
\hline $90 \mathrm{~A}$ & 1.518 & 1.138 & 0.380 \\
$100 \mathrm{~A}$ & 1.638 & 1.326 & 0.312 \\
$110 \mathrm{~A}$ & 1.642 & 1.592 & 0.050 \\
$120 \mathrm{~A}$ & 1.976 & 1.766 & 0.210 \\
$130 \mathrm{~A}$ & 2.450 & 2.126 & 0.324 \\
\hline
\end{tabular}

* units in $(\mathrm{mm})$

DCRP polarity at $110 \mathrm{~A}$ has a penetration depth of $1.642 \mathrm{~mm}$ and a difference of 0.05 $\mathrm{mm}$ deeper than the DCSP which only has a depth of $1.592 \mathrm{~mm}$. The polarity of DCRP at 120 A has a depth of $1.976 \mathrm{~mm}$ and a difference of $0.21 \mathrm{~mm}$ is deeper than DCSP which only has a depth of $1.766 \mathrm{~mm}$. DCRP polarity at 130 A has a depth of $2.45 \mathrm{~mm}$ and a difference of $0.324 \mathrm{~mm}$ is deeper than DCSP which only has a depth of $2.126 \mathrm{~mm}$. 
Overall results show that the depth of penetration in the polarity type DCRP is deeper than the polarity of the DCSP type. It is in accordance with the previous explanation that the polarity of DCRP produces a temperature of $4200{ }^{\circ} \mathrm{C}$ compared to DCSP, which only produces a temperature of $3800{ }^{\circ} \mathrm{C}$.

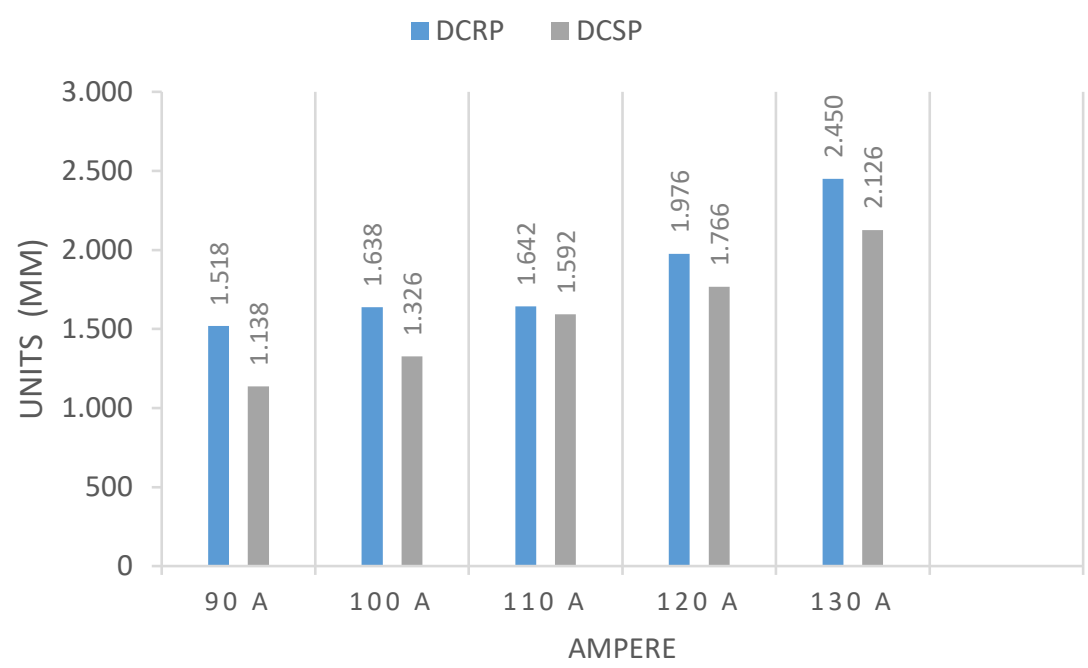

Fig. 12. Comparison of depth penetration DCRP and DCSP

\section{Conclusions}

The effect of polarity DCRP (Direct Current Reverse Polarity) and DCSP (Direct Current Straight Polarity) on the penetration depth of SMAW (Shielded Metal Arc Welding) welding using Electrode E7018 LB-52-18 $3.2 \mathrm{~mm}$ with an arc welding angle of $70^{\circ}$ and the use of carbon steel ASTM A36 is low using DCRP is deeper at each current level. The influence of the current magnitude also affects the penetration results. If the current is higher, it will get a deep penetration result. The depth of deep penetration will make the value of the strength of the weld increase.

\section{References}

[1] Putra, A., and Wulandari, D., "Effect of Welding Polarity and Electrode Type on Tensile Strength and Toughness of SMAW Welding," J. Pendidik. Tek. Mesin UNESA, vol. 6(01), 250958, 2017 (in Indonesia).

[2] Santos, S., Jaganathan, S., Anantha, R., L, and Balmurugan, M., "Experimentation and Comparative Study of E6013 and E7018 Weldments Using Shielded Metal Arc Welding E7018 Weldments Using Shielded Metal Arc Welding," Int. J. Mech. Prod. Eng. Res. Dev., vol. 8, pp. 174, 2018.

[3] Kumar, B.,S., P., and Vijayakumar, Y., "Selection of Optimum Process Parameters of Shielded Metal Arc Welding (SMAW) to Weld Steel Pipes by Design of Experiments," Intern. J. of Engineering Research and Applications, vol. 2(5), pp. 377-381, 2012.

[4] Kahfi, A., "Pengaruh Kuat Arus terhadap Hasil Pengelasan Las GMAW pada Baja 
ASTM A36," J. Ilm. Tek. Mesin, vol. 7(1), pp. 1-53, 2016.

[5] Pathirana, S.D., Weerasekralage, L. S. S. K, and Karunaratne, M., "Optimization of Shielded Metal Arc Welding (SMAW) process for mild steel", Transaction Part B: Technical Paper. Annual Sessions of IESL, pp. 841 - 847, 2019.

[6] Sulaiman, S. A., Abdullah, B., Alias, S. K., Ahmad, N. N., and Aziz, M. N. A., "Investigation of corrosion rate for different type of welding joints using shielded metal arc welding (SMAW),” IOP Conf. Ser. Mater. Sci. Eng., vol. 834(1), 2020, doi: 10.1088/1757-899X/834/1/012055.

[7] Pagare, R., Awati, D., Mane, S., Teli, V., and Bhandare, A., "Investigating the Effects of Welding Parameters on Mild Steel by SMAW Technique," IOP Conf. Ser. Mater. Sci. Eng., vol. 998(1), 7, 2020, doi: 10.1088/1757-899X/998/1/012052.

[8] Surasno, "Analisa Polaritas terhadap Kedalaman Penetrasi dan Dilusi dari Proses SMAW pada Baja Karbon Rendah ASTM A36.” Berita Teknologi Bahan dan Barang Teknik, p. 10, 2005.

[9] Rahangmetan, K. A., Wullur, C. W., and Sariman, F., "Effect Variations and Types of Smaw Welding Electrodes on A36 Steel to Tensile Test," J. Phys. Conf. Ser., vol. 1569 (3), 6, 2020, doi: 10.1088/1742-6596/1569/3/032052.

[10] Howard, H., and Gerrish, "Electricity and Electronics," Good Hear. Co, Inc., 1968.

[11] Ambiyari, Teknik Pembentukan Plat, vol. 53(9), 2019.

[12] American Welding Society, Specification for Carbon Steel Electrodes for Shielded Metal Arc Welding. American Welding Society I. 2004.

[13] Kobe-Steel, "Kobelco Welding Handbook, Welding Consumables and Processes," 2008.

[14] Suherman, S., Muhammadiyah, U., Utara, S., and Mizhar, S. "Effect of Electrode on Welding Joint of Steel Sa106 Grade A Using SMAW," Rotasi, vol. 22, p. 252, 2020, (in Indonesia). doi: 10.14710/rotasi.22.4.246-252.

[15] Hatta, I., "Aplication of Micro Analysis and Fractograhy to Determine the Product Quality and Cause of Damage of Component," Pros. Pertem. Ilm. Ilmu Pengetah. dan Teknol. Bahan, vol. 30(c), pp. 175-180, 2012 (in Indonesia).

[16] Sari A. L., and Rusiyanto, R., "Effect of Thermal Shock Resistance and Composition of Refractory Materials on Impact Strength and Macro Structure," J.Din. Vokasional Tek. Mesin, vol. 4(2), pp. 105-110, 2019 (in Indonesia). doi: 10.21831/dinamika.v4i2.27392.

[17] ASM Handbook, "Metallography and Microstructures,” vol. 9, ASM International, 2004. 